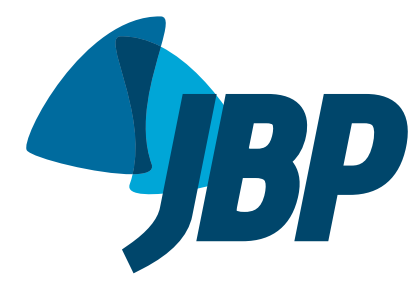

\title{
Estimated rates of recurrence, cure, and treatment abandonment in patients with pulmonary tuberculosis treated with a four-drug fixed-dose combination regimen at a tertiary health care facility in the city of Rio de Janeiro, Brazil
}

\author{
Vangie Dias da Silva', Fernanda Carvalho de Queiroz Mello², \\ Sonia Catarina de Abreu Figueiredo ${ }^{2}$
}

1. Programa de Pós-Graduação, Universidade Federal do Rio de Janeiro, Rio de Janeiro (RJ) Brasil.

2. Faculdade de Medicina, Universidade Federal do Rio de Janeiro, Rio de Janeiro (RJ) Brasil.

Submitted: 8 July 2016.

Accepted: 31 October 2016.

Study carried out at Hospital Universitário Clementino Fraga Filho - HUCFF Instituto de Doenças do Tórax - IDT Universidade Federal do Rio de Janeiro, Rio de Janeiro (RJ) Brasil.

\begin{abstract}
Objective: To estimate the rates of recurrence, cure, and treatment abandonment in patients with pulmonary tuberculosis treated with a four-drug fixed-dose combination (FDC) regimen, as well as to evaluate possible associated factors. Methods: This was a retrospective observational study involving 208 patients with a confirmed diagnosis of pulmonary tuberculosis enrolled in the Hospital Tuberculosis Control Program at the Institute for Thoracic Diseases, located in the city of Rio de Janeiro, Brazil. Between January of 2007 and October of 2010, the patients were treated with the rifampinisoniazid-pyrazinamide $(\mathrm{RHZ})$ regimen, whereas, between November of 2010 and June of 2013, the patients were treated with the rifampin-isoniazid-pyrazinamide-ethambutol FDC (RHZE/FDC) regimen. Data regarding tuberculosis recurrence and mortality in the patients studied were retrieved from the Brazilian Case Registry Database and the Brazilian Mortality Database, respectively. The follow-up period comprised two years after treatment completion. Results: The rates of cure, treatment abandonment, and death were $90.4 \%, 4.8 \%$, and $4.8 \%$, respectively. There were 7 cases of recurrence during the follow-up period. No significant differences in the recurrence rate were found between the RHZ and RHZE/FDC regimen groups ( $p=0.13$ ). We identified no factors associated with the occurrence of recurrence; nor were there any statistically significant differences between the treatment groups regarding adverse effects or rates of cure, treatment abandonment, or death. Conclusions: The adoption of the RHZE/ FDC regimen produced no statistically significant differences in the rates of recurrence, cure, or treatment abandonment; nor did it have any effect on the occurrence of adverse effects, in comparison with the use of the $\mathrm{RHZ}$ regimen.
\end{abstract}

Keywords: Tuberculosis, pulmonary, Drug combinations; Recurrence.

\section{INTRODUCTION}

Tuberculosis remains a serious global public health problem and is one of the leading causes of death in the world, according to data from the World Health Organization. Brazil is one of the 22 countries that collectively account for $80.0 \%$ of all cases of pulmonary tuberculosis worldwide, ranking 18th. In 2014, the tuberculosis incidence rate in Brazil was 44 cases per 100,000 population, with a rate of tuberculosis/HIV coinfection of $17 \%$. The mortality rate from tuberculosis/HIV was 1.2 cases per 100,000

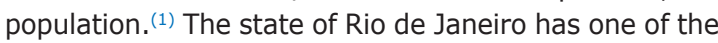
highest tuberculosis incidence rates in the country ( 54.5 cases $/ 100,000$ population), second only to the state of Amazonas, as well as having the highest mortality rate from tuberculosis in the country (5.1 cases/100,000 population) and a rate of tuberculosis/HIV coinfection of $8.9 \%{ }^{(2)}$ Tuberculosis is related to poverty, malnutrition, and social exclusion,(3) predominating in men aged 45 to 59 years. ${ }^{(3,4)}$

Since 1994, the World Health Organization and the International Union against Tuberculosis and Lung Diseases have recommended the use of fixed-dose combinations (FDCs), proposing the change in previous treatments with the justification that treatment adherence would be better and selection of drug-resistant mutant bacilli would be reduced, ${ }^{(4-8)}$ which would translate to higher cure rates and lower rates of treatment abandonment, recurrence, and death.

On the basis of data from the Second National Survey on Antituberculosis Drug Resistance (2007-2008), ${ }^{(4,9)}$ which showed an increase in primary resistance to isoniazid (from $3.5 \%$ to $6 \%$ ) and rifampin (from $0.2 \%$ to $1.5 \%$ ) between 1997 and 2007, the Brazilian National Tuberculosis Control Program/Ministry of Health decided, 
in 2009 , to change the regimen used, which had been in use since 1979. The regimen that had been used until then, known as regimen I-2 months of rifampin, isoniazid, and pyrazinamide $(\mathrm{RHZ})$, followed by 4 months of rifampin and isoniazid $(\mathrm{RH})$-was changed by adding a fourth drug, ethambutol, to the (2-month) intensive phase of treatment, the new regimen being designated $2 \mathrm{RHZE} / 4 \mathrm{RH}$. In the 2-month intensive phase of treatment, capsules were replaced by FDC tablets containing RHZE (RHZE/FDC), whereas, in the 4-month continuation phase of treatment, FDC capsules containing $\mathrm{RH}$ were used. In adults, the doses of isoniazid and pyrazinamide were adjusted to 300 $\mathrm{mg} /$ day and $1,600 \mathrm{mg} /$ day, respectively. ${ }^{(4,9)}$

The objective of the present study was to determine the rate of recurrence of pulmonary tuberculosis with the use of the RHZE/FDC regimen, in comparison with the use of regimen I ( $\mathrm{RHZ}$ ), and to identify possible risk factors leading to recurrence, in addition to determining the rates of cure, treatment abandonment, and death, as well as the occurrence of adverse effects.

\section{METHODS}

This was a retrospective observational study conducted between January of 2007 and June of 2013 at the Instituto de Doenças do Tórax (IDT, Institute for Thoracic Diseases) of Hospital Universitário Clementino Fraga Filho (HUCFF, Clementino Fraga Filho University Hospital), which is a tertiary hospital complex affiliated with the Federal University of Rio de Janeiro and is located in the north area of the city of Rio de Janeiro, Brazil. The hospital is a referral center for the treatment of patients with HIV/AIDS, patients with diseases requiring complex treatment, such as transplantation, patients with autoimmune diseases, cancer patients, and patients with diabetes mellitus; therefore, comorbidities are common. The study was approved by the HUCFF/IDT Research Ethics Committee in November of 2013 (Protocol no. 465.507).

At the HUCFF/IDT, there is the Programa de Controle da Tuberculose Hospitalar (PCTH, Hospital Tuberculosis Control Program), which was established in 1998. The program includes active surveillance for tuberculosis in inpatients, outpatient treatment for patients suspected of having tuberculosis, isolation of patients with suspected or confirmed pulmonary tuberculosis, routine sputum smear microscopy and mycobacterial culture, prompt availability of laboratory results, and continuing education of health care professionals. It is a multidisciplinary integrated care program, and all enrolled patients are followed for 2 years after treatment completion. ${ }^{(10)}$

The medical records of all patients treated at the PCTH outpatient clinic during the study period were reviewed by using a data collection instrument, and confidentiality was maintained. In addition to information on sociodemographic variables (gender, age, and level of education), information was collected on clinical and epidemiological variables (nutritional status, date of the first episode of tuberculosis, date of recurrence, and HIV serology), lifestyle habits (alcohol consumption, smoking, smoking history, and illicit drug use), and presence of comorbidities. All patients enrolled in the PCTH for treatment were followed for 2 years after treatment completion in order to determine whether or not there were recurrences. Patient data on recurrence and mortality during the 2-year follow-up period were retrieved from the Brazilian Ministry of Health National Case Registry Database and the Brazilian Mortality Database, respectively. The search was done using the patient's name, the patient's mother's name, and the patient's date of birth.

During treatment through the $\mathrm{PCTH}$, all patients were followed monthly and were asked about the occurrence of adverse effects, by using a standardized data collection instrument, which included adverse reactions; these data were entered into a PCTH database. Adverse effects were classified as minor and major. Major adverse effects, namely, hepatitis, rifampin-induced thrombocytopenia, hemolytic anemia, acute renal failure, thrombotic thrombocytopenic purpura, ethambutol-induced optic neuritis, and pyrazinamide-induced acute gouty arthritis, require discontinuation of the offending drug and a change in the initial regimen. ${ }^{(6)}$ Minor adverse effects include skin rash, acne, itching, arthralgia, and mild gastrointestinal symptoms, such as nausea, vomiting, loss of appetite, and abdominal pain; in cases of patients exhibiting these effects, it is usually not necessary to change treatment, and patient management consists of symptomatic therapy and a change in the administration schedule. ${ }^{(6)}$

Statistical analysis was performed with the Statistical Analysis System, version 6.11 (SAS Institute Inc., Cary, NC, USA). Descriptive statistics were expressed as frequency $(n)$ and proportion (\%) for categorical data and as mean and standard deviation for numerical data. In order to determine whether sociodemographic variables, comorbidities, and adverse effects were significantly associated with recurrence, categorical data were compared by using the chi-square test or Fisher's exact test, and numerical data (continuous variables with normal distribution) were compared by using the Student's t-test for independent samples. The level of statistical significance was set at 5\% ( $<<0.05)$.

\section{RESULTS}

Of the 466 patients treated for pulmonary tuberculosis through the PCTH during the study period, 275 were included. All of those 275 patients were 18 years of age or older; had a diagnosis of pulmonary tuberculosis confirmed by culture, which was performed through the PCTH; and were considered cured or completed treatment, either with regimen I ( $\mathrm{RHZ}$ ) between January of 2007 and October of 2010 or with the RHZE/FDC regimen between November of 2010 and June of 2013. Sixty-seven patients were excluded for different reasons (Figure 1). The final sample for the analysis of the rates of cure, treatment abandonment, and death, as well as for the assessment of adverse 


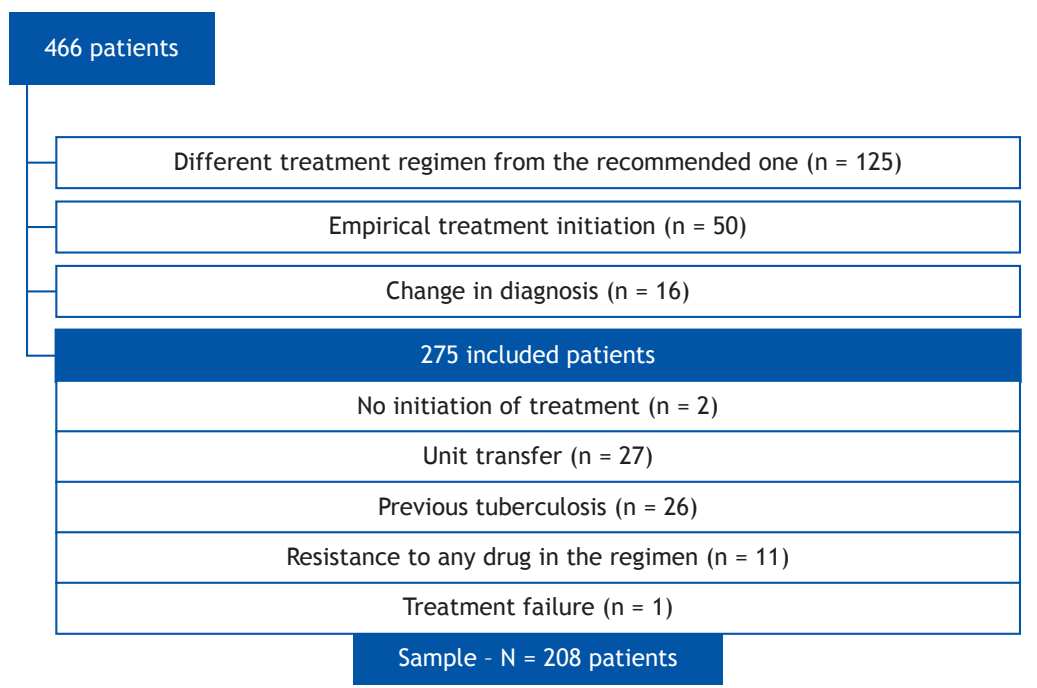

Figure 1. Selection of patients diagnosed with pulmonary tuberculosis for inclusion in the study.

effects, consisted of 208 patients, all of whom underwent self-administered treatment (Figure 1).

In the sample of 208 patients for the assessment of adverse effects and analysis of the rates of cure, treatment abandonment, and death, 125 patients $(60.1 \%)$ received the $\mathrm{RHZ}$ regimen (in capsules and tablets) e 83 patients (39.9\%) received the RHZE/ FDC regimen.

The pattern of involvement by tuberculosis (first episode), with sociodemographic and clinical variables being stratified by treatment regimen (two groups), is shown in Table 1.

Among the 203 patients for whom data on adverse effects were available (information unavailable for 5 ), 139 experienced adverse effects (68.5\%). There were no significant differences in the occurrence of adverse effects between the two treatment groups (Table 2).

Table 3 shows data on treatment status and outcomes by treatment regimen. The overall cure rate was $90.4 \%$, and the rates of treatment abandonment and death before treatment completion were both 4.8\%. During the 2-year follow-up period, 11 patients died from various causes. There were no significant differences in those rates between the two treatment groups. It was necessary to change the initial treatment because of the occurrence of adverse effects in 24 patients (18 in the $\mathrm{RHZ}$ group and 6 in the RHZE/FDC group), with no statistical difference ( $p=0.11$; Table 3).

For the analysis of the recurrence rate, we excluded 21 cases of death from any cause during treatment or during the 2-year follow-up period after treatment completion (4 of which experienced adverse effects and had a change in treatment regimen); 10 cases of treatment abandonment ( 1 of which experienced adverse effects and had a change in treatment regimen); and 24 cases of change in treatment regimen due to drug intolerance. Therefore, for this analysis, we excluded 50 patients, and the final sample consisted of 158 patients $(78.9 \%)$. There were 7 recurrences throughout the follow-up period (recurrence rate $=4.4 \%$ ), 6 of which occurred in the $\mathrm{RHZ}$ group and 1 of which occurred in the RHZE/FDC group, with no statistical difference ( $p$ $=0.13$ ). Only 4 recurrences occurred within 2 years after treatment $(\mathrm{RHZ}=3$ patients and $\mathrm{RHZE} / \mathrm{FDC}=$ 1 patient), the recurrence rate in this period being $2.5 \%$. The other 3 recurrences occurred later than the two years of treatment and follow-up.

Smoking, illicit drug use, alcoholism, positive HIV serology, and body mass index (BMI) $<18.5 \mathrm{~kg} / \mathrm{cm}^{2}$ were not risk factors for recurrence (Table 4 ), nor was the presence of comorbidities, the presence of cavitation on chest X-ray, or the occurrence of a positive culture at 2 months of treatment. Time to culture conversion ( 2 months) was not different between the groups ( $p$ $=0.36$ ). There were only 7 cases of positive culture at 2 months (4.8\%). This information was available for 145 patients $(69.7 \%)$

Of the 208 patients, 146 (70.2\%) had comorbidities when they developed tuberculosis. Among those who had recurrence, comorbidity-related characteristics were as follows: hepatitis, in 1 ; systemic arterial hypertension, in 2 ; diabetes mellitus, in 1 ; insulin dependence, in 1 ; chronic renal failure, in 1 ; connective tissue disease, in 2; use of immunosuppressants, in 2; use of corticosteroids, in 2; and lung disease, in 2. None of the comorbidities were found to be statistically associated with the recurrence outcome. There were no associations between the occurrence of major or minor adverse effects and recurrence.

\section{DISCUSSION}

Our study did not find statistically significant differences in the recurrence rate between the $\mathrm{RHZ}$ and RHZE/FDC groups, nor did it find associations of this outcome with the clinical factors investigated. There were no statistically significant differences in the occurrence of adverse effects between the groups, either. Malnutrition ( $p=0.079)$, connective tissue 
Estimated rates of recurrence, cure, and treatment abandonment in patients with pulmonary tuberculosis treated with a four-drug

Table 1. Sociodemographic and clinical variables by treatment regimen.

\begin{tabular}{|c|c|c|c|c|c|}
\hline \multirow[t]{3}{*}{ Variable } & \multicolumn{4}{|c|}{ Treatment regimen } & \multirow[t]{3}{*}{ p } \\
\hline & \multicolumn{2}{|c|}{$\begin{array}{c}\text { RHZ } \\
(n=125)\end{array}$} & \multicolumn{2}{|c|}{$\begin{array}{c}\text { RHZE/FDC } \\
(\mathbf{n}=83)\end{array}$} & \\
\hline & $n$ & $\%$ & $\mathrm{n}$ & $\%$ & \\
\hline \multicolumn{6}{|l|}{ Gender } \\
\hline Male & 81 & 64.8 & 45 & 54.2 & \multirow{2}{*}{0.13} \\
\hline Female & 44 & 35.2 & 38 & 45.8 & \\
\hline Age, years ${ }^{a}$ & $46 \pm 17$ & & $42 \pm 15$ & & $0.11^{*}$ \\
\hline \multicolumn{6}{|l|}{ Age group, years } \\
\hline$\leq 30$ & 29 & 23.2 & 21 & 25.3 & \multirow{4}{*}{$0.65^{*}$} \\
\hline $31-44$ & 31 & 24.8 & 26 & 31.3 & \\
\hline $45-55$ & 33 & 26.4 & 18 & 21.7 & \\
\hline$>55$ & 32 & 25.6 & 18 & 21.7 & \\
\hline \multicolumn{6}{|l|}{ Race $^{b}$} \\
\hline White & 63 & 50.4 & 39 & 47.6 & \multirow{3}{*}{0.015} \\
\hline Biracial & 32 & 25.6 & 34 & 41.5 & \\
\hline Black & 30 & 24 & 9 & 11.0 & \\
\hline \multicolumn{6}{|l|}{ Level of educationc } \\
\hline Illiterate/ $\leq 9$ years of schooling & 65 & 54.6 & 38 & 48.1 & \multirow{3}{*}{0.46} \\
\hline High school (incomplete/complete) & 38 & 31.9 & 32 & 40.5 & \\
\hline College (incomplete/complete) & 16 & 13.4 & 9 & 11.4 & \\
\hline \multicolumn{6}{|l|}{ Smoking ${ }^{c}$} \\
\hline Yes & 18 & 14.6 & 8 & 9.6 & \multirow{3}{*}{0.45} \\
\hline Former smoker & 43 & 35 & 27 & 32.5 & \\
\hline No & 62 & 50.4 & 48 & 57.8 & \\
\hline \multicolumn{6}{|l|}{ Smoking history, pack-years ${ }^{c}$} \\
\hline 0 & 62 & 54.9 & 48 & 63.2 & \multirow{3}{*}{0.43} \\
\hline$\leq 20$ & 18 & 15.9 & 12 & 15.8 & \\
\hline$>20$ & 33 & 29.2 & 16 & 21.1 & \\
\hline \multicolumn{6}{|l|}{ Drug use ${ }^{c}$} \\
\hline Yes & 9 & 7.5 & 4 & 4.9 & \multirow{2}{*}{0.47} \\
\hline No & 111 & 92.5 & 77 & 95.1 & \\
\hline \multicolumn{6}{|l|}{ BMI classification ${ }^{c}$} \\
\hline Underweight & 19 & 23.2 & 16 & 27.6 & \multirow{3}{*}{0.83} \\
\hline Normal weight & 47 & 57.3 & 31 & 53.4 & \\
\hline Overweight/obese & 16 & 19.5 & 11 & 19.0 & \\
\hline \multicolumn{6}{|l|}{ Alcoholism ${ }^{c}$} \\
\hline Yes & 23 & 18.5 & 8 & 9.8 & \multirow{2}{*}{0.084} \\
\hline No & 101 & 81.5 & 74 & 90.2 & \\
\hline \multicolumn{6}{|l|}{ HIV serologyc } \\
\hline Positive & 18 & 15.3 & 6 & 9.0 & \multirow{2}{*}{0.22} \\
\hline Negative & 100 & 84.7 & 61 & 91.0 & \\
\hline
\end{tabular}

RHZ: rifampin-isoniazid-pyrazinamide; RHZE/FDC: rifampin-isoniazid-pyrazinamide-ethambutol fixed-dose combination;

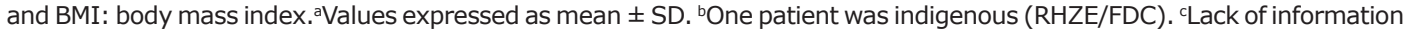
on the following variables: level of education $(n=10)$; smoking $(n=2)$; smoking history $(n=19)$; drug use $(n=7)$; BMI classification ( $n=68)$; alcoholism $(n=2)$; and HIV serology $(n=23)$. *Student's t-test for independent samples.

disease $(p=0.12)$, and use of immunosuppressants or corticosteroids showed a trend toward an association with recurrence, although the association was not statistically significant. There were no differences in the rates of cure, treatment abandonment, or death between the treatment groups, the change in treatment to RHZE/FDC not translating to improvement in those rates, as has been reported in the literature. ${ }^{(8,11-16)}$

Tuberculosis was predominant in males (60.6\%), in the economically active age group (27.4\%), in
Whites $(49.0 \%)$, and in patients with a low level of education $(52.0 \%)$. A low level of education suggests low socioeconomic status and limited access to health care. ${ }^{(3,17)}$ There were no differences in sociodemographic variables between the treatment groups ( $\mathrm{RHZ}$ vs. RHZE/FDC), showing that the groups were comparable.

In our sample, 89 patients $(43.4 \%)$ had chest $X$-ray findings suggestive of tuberculosis with cavitation, and there were only 7 cases $(4.8 \%)$ of positive culture at 2 months of treatment. Although it has been reported 
Table 2. Adverse effects by treatment regimen. ${ }^{\mathrm{a}}$

\begin{tabular}{|c|c|c|c|c|c|}
\hline \multirow[t]{3}{*}{ Adverse effects } & \multicolumn{4}{|c|}{ Treatment regimen } & \multirow[t]{3}{*}{$\mathbf{p}$} \\
\hline & \multicolumn{2}{|c|}{ RHZ } & \multicolumn{2}{|c|}{ RHZE/FDC } & \\
\hline & $n$ & $\%$ & n & $\%$ & \\
\hline \multicolumn{6}{|l|}{ Total } \\
\hline Yes & 86 & 69.9 & 53 & 66.3 & 0.35 \\
\hline No & 37 & 30.1 & 27 & 33.8 & \\
\hline \multicolumn{6}{|l|}{ Minor } \\
\hline Yes & 78 & 63.4 & 48 & 60.0 & 0.37 \\
\hline No & 45 & 36.6 & 32 & 40.0 & \\
\hline \multicolumn{6}{|l|}{ Major } \\
\hline Yes & 14 & 11.4 & 7 & 8.8 & 0.36 \\
\hline No & 109 & 88.6 & 73 & 91.3 & \\
\hline \multicolumn{6}{|l|}{ Acne/itching } \\
\hline Yes & 31 & 25.2 & 13 & 16.3 & 0.089 \\
\hline No & 92 & 74.8 & 67 & 83.8 & \\
\hline \multicolumn{6}{|l|}{ Arthralgia } \\
\hline Yes & 34 & 27.6 & 15 & 18.8 & 0.099 \\
\hline No & 89 & 72.4 & 65 & 81.3 & \\
\hline \multicolumn{6}{|c|}{ Anorexia/vomiting/abdominal pain/nausea } \\
\hline Yes & 39 & 31.7 & 26 & 32.5 & 0.51 \\
\hline No & 84 & 68.3 & 54 & 67.5 & \\
\hline \multicolumn{6}{|l|}{ Paresthesia } \\
\hline Yes & 21 & 17.1 & 15 & 18.8 & 0.45 \\
\hline No & 102 & 82.9 & 65 & 81.3 & \\
\hline \multicolumn{6}{|l|}{ Hepatotoxicity } \\
\hline Yes & 13 & 10.6 & 6 & 7.5 & 0.32 \\
\hline No & 110 & 89.4 & 74 & 92.5 & \\
\hline \multicolumn{6}{|l|}{ Optic neuritis } \\
\hline Yes & 0 & 0 & 0 & 0 & N/A \\
\hline No & 123 & 100 & 80 & 100 & \\
\hline \multicolumn{6}{|l|}{ Exanthema } \\
\hline Yes & 1 & 0.8 & 1 & 1.3 & 0.63 \\
\hline No & 122 & 99.2 & 79 & 98.8 & \\
\hline
\end{tabular}

RHZ: rifampin-isoniazid-pyrazinamide; and RHZE/FDC: rifampin-isoniazid-pyrazinamide-ethambutol fixed-dose combination. aLack of information on 5 patients ( 2 in the RHZ group and 3 in the RHZE/FDC group). Patients could experience more than one adverse effect.

Table 3. Treatment status and variables by treatment regimen. ${ }^{a}$

\begin{tabular}{|c|c|c|c|c|c|}
\hline \multirow[t]{3}{*}{ Variable } & \multicolumn{4}{|c|}{ Treatment regimen } & \multirow[t]{3}{*}{$p$} \\
\hline & \multicolumn{2}{|c|}{$\begin{array}{c}\text { RHZ } \\
(n=125)\end{array}$} & \multicolumn{2}{|c|}{$\begin{array}{c}\text { RHZE/FDC } \\
(n=83)\end{array}$} & \\
\hline & $\mathbf{n}$ & $\%$ & $\mathbf{n}$ & $\%$ & \\
\hline \multicolumn{6}{|l|}{ Treatment status } \\
\hline Cure & 114 & 91.2 & 74 & 89.2 & \\
\hline Treatment abandonment & 4 & 3.2 & 6 & 7.2 & 0.32 \\
\hline Death & 7 & 5.6 & 3 & 3.6 & \\
\hline \multicolumn{6}{|c|}{ Positive culture at 2 months of treatment } \\
\hline Yes & 3 & 3.7 & 4 & 6.3 & 0.36 \\
\hline No & 79 & 96.3 & 59 & 93.7 & \\
\hline \multicolumn{6}{|l|}{ Change in initial treatment } \\
\hline Yes & 18 & 14.4 & 6 & 7.2 & 0.11 \\
\hline No & 107 & 85.6 & 77 & 92.8 & \\
\hline \multicolumn{6}{|l|}{ Recurrence } \\
\hline Yes & 6 & 4.8 & 1 & 1.2 & 0.13 \\
\hline No & 119 & 95.2 & 82 & 98.8 & \\
\hline
\end{tabular}

RHZ: rifampin-isoniazid-pyrazinamide; and RHZE/FDC: rifampin-isoniazid-pyrazinamide-ethambutol fixed-dose combination. 
Estimated rates of recurrence, cure, and treatment abandonment in patients with pulmonary tuberculosis treated with a four-drug fixed-dose combination regimen at a tertiary health care facility in the city of Rio de Janeiro, Brazil

Table 4. Sociodemographic and clinical variables by recurrence status $(\mathrm{N}=158)$.

\begin{tabular}{|c|c|c|c|c|c|}
\hline \multirow[t]{2}{*}{ Variable } & \multicolumn{2}{|c|}{ Recurrence } & \multicolumn{2}{|c|}{ No recurrence } & \multirow[t]{2}{*}{$\mathbf{p}$} \\
\hline & $\mathbf{n}$ & $\%$ & $\mathbf{n}$ & $\%$ & \\
\hline \multicolumn{6}{|l|}{ Gender } \\
\hline Male & 4 & 57.1 & 88 & 58.3 & \multirow[t]{2}{*}{0.62} \\
\hline Female & 3 & 42.9 & 63 & 41.7 & \\
\hline Age, years ${ }^{a}$ & $44 \pm 15$ & & $42 \pm 15$ & & \\
\hline \multicolumn{6}{|l|}{ Age group, years } \\
\hline$\leq 30$ & 1 & 14.3 & 42 & 27.8 & \multirow[t]{4}{*}{0.61} \\
\hline $31-44$ & 2 & 28.6 & 42 & 27.8 & \\
\hline $45-55$ & 3 & 42.9 & 34 & 22.5 & \\
\hline$>55$ & 1 & 14.3 & 33 & 21.9 & \\
\hline \multicolumn{6}{|l|}{ Race } \\
\hline White & 2 & 28.6 & 69 & 46.0 & \multirow[t]{3}{*}{0.45} \\
\hline Biracial & 4 & 57.1 & 51 & 34 & \\
\hline Black & 1 & 14.3 & 30 & 20.0 & \\
\hline \multicolumn{6}{|l|}{ Level of education } \\
\hline Illiterate $/ \leq 9$ years of schooling & 3 & 42.9 & 75 & 52.1 & \multirow[t]{3}{*}{0.87} \\
\hline High school (incomplete/complete) & 3 & 42.9 & 49 & 34.0 & \\
\hline College (incomplete/complete) & 1 & 14.3 & 20 & 13.9 & \\
\hline \multicolumn{6}{|l|}{ Smoking } \\
\hline Yes & 1 & 14.3 & 20 & 13.4 & \multirow[t]{3}{*}{0.97} \\
\hline Former smoker & 2 & 28.6 & 49 & 32.9 & \\
\hline No & 4 & 57.1 & 80 & 53.7 & \\
\hline \multicolumn{6}{|l|}{ Smoking history, pack-years ${ }^{\mathrm{b}}$} \\
\hline 0 & 4 & 66.7 & 80 & 59.3 & \multirow[t]{3}{*}{0.33} \\
\hline$\leq 20$ & 2 & 33.3 & 24 & 17.8 & \\
\hline$>20$ & 0 & 0.0 & 31 & 23.0 & \\
\hline \multicolumn{6}{|l|}{ Drug use } \\
\hline Yes & 1 & 14.3 & 10 & 6.8 & \multirow[t]{2}{*}{0.41} \\
\hline No & 6 & 85.7 & 136 & 93.2 & \\
\hline \multicolumn{6}{|l|}{ BMI classification } \\
\hline Underweight & 3 & 75 & 24 & 24.7 & \multirow[t]{3}{*}{0.079} \\
\hline Normal weight & 1 & 25 & 53 & 54.6 & \\
\hline Overweight/obese & 0 & 0.0 & 20 & 20.6 & \\
\hline \multicolumn{6}{|l|}{ Alcoholism } \\
\hline Yes & 1 & 14.3 & 21 & 14.1 & \multirow[t]{2}{*}{0.66} \\
\hline No & 6 & 85.7 & 128 & 85.9 & \\
\hline \multicolumn{6}{|l|}{ HIV serology } \\
\hline Positive & 1 & 14.3 & 18 & 13.2 & \multirow[t]{2}{*}{0.64} \\
\hline Negative & 6 & 85.7 & 118 & 86.8 & \\
\hline
\end{tabular}

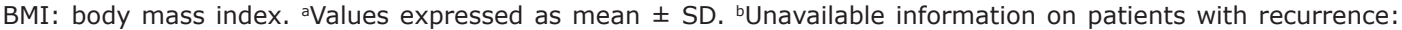
smoking history, in 1; and BMI classification, in 3.

in the literature that cavitation is a risk factor for recurrence ${ }^{(1,18-21)}$, as is the occurrence of a positive culture at 2 months of treatment, ${ }^{(1820,22)}$ this was not observed in the present study.

There was a trend toward increased occurrence of cutaneous adverse effects (acne/itching) and arthralgia in the $\mathrm{RHZ}$ regimen group. This trend might be explained by the higher dose concentrations of isoniazid and pyrazinamide in the $\mathrm{RHZ}$ regimen, in comparison with the RHZE/FDC regimen. Despite the possibility that the addition of ethambutol could cause more cases of optic neuritis, no such cases were observed. Some studies have not found differences in the occurrence of adverse effects between single-drug regimens and FDC regimens, corroborating our study results. $(9,13-15)$ Gravendeel et al. found increased occurrence of adverse effects in the single-drug regimen group, and gastrointestinal and musculoskeletal adverse effects predominated. (12) According to the literature, the main advantages of changing treatment to FDCs include improving adherence, simplifying treatment, and preventing monotherapy and subsequent selection of drug-resistant mutant bacilli. $(6,11,23,24)$

Only 4 recurrences occurred within 2 years after treatment $(\mathrm{RHZ}=3$ patients and RHZE/FDC $=1$ patient), the recurrence rate in this period being 
$2.5 \%$, which is similar to previous reports. ${ }^{(13,25)}$ There was a trend toward increased recurrence in the $\mathrm{RHZ}$ regimen group. Some authors have found that changing treatment to RHZE/FDCs led to a trend toward increased recurrence. ${ }^{(11,25-27)}$ In contrast, other studies have found no differences in the recurrence rate between the groups (FDC vs. single-drug formulation). ${ }^{(8,15)} \mathrm{A}$ recently published review found little or no difference in the rates of death or in the frequency of adverse effects between the groups. ${ }^{(27)}$ FDCs had no effect in reducing the treatment abandonment rate or the irregular use of drugs. ${ }^{(5,9,13,15,23)}$ The treatment abandonment rate in our study did not vary in a statistically significant way in the two groups, possibly because of the integrated multidisciplinary care provided through the PCTH. ${ }^{(10)}$

Our study has some limitations, such as the sample size, that may have prevented us from detecting significant associations. A convenience sample was used, because this was a study limited to the operational routine of a single facility. The fact that it was retrospective is another limitation, since data collection by using a data collection instrument and reviewing medical charts may have prevented the gathering of some information. In addition, patients with tuberculosis having access to the HUCFF/IDT meant that most of them had comorbidities, limiting the external validity of the findings. The sample size was not calculated to compare the recurrence rate with RHZE/FDC and RHZ or to compare patients with and without recurrence.
However, the fact that this was a study conducted at a tuberculosis treatment facility that provides integrated multidisciplinary care, ${ }^{(10)}$ associated with bacteriological confirmation with routine profiling of sensitivity to the drugs in the regimens used, postcure follow-up, standardized routines, and systematic data collection, may contribute to the analysis of the effects that the RHZE/FDC regimen has, under optimal operational conditions, on the care of patients with active tuberculosis.

In conclusion, changing treatment to a four-drug FDC produced no statistically significant differences in the rates of recurrence, in comparison with the use of the previous regimen. We identified a trend toward a BMI $<18.5 \mathrm{~kg} / \mathrm{cm}^{2}$ and connective tissue disease being risk factors for recurrence, a trend that may not have reached the level of statistical significance because of the sample size. There were no statistically significant differences in the rates of treatment abandonment, death, or cure or in the occurrence of major or minor adverse effects between the groups. However, the $\mathrm{RHZ}$ regimen group showed a trend toward a higher incidence of cutaneous adverse effects (acne/itching) and arthralgia than did the RHZE/FDC regimen group. Further studies involving larger samples and data on different operational routines than that of the PCTH/ HUCFF/IDT could contribute to elucidating the impact of the use of the RHZE/FDC regimen in Brazil.

\section{REFERENCES}

1. World Health Organization. Global Tuberculosis report 2015. Geneva: World Health Organization; 2015.

2. Brasil. Ministério da Saúde. Secretária de Vigilância à Saúde. Perspectivas brasileiras para o fim da tuberculose como problema de saúde pública. Brasília: o Ministério. Boletim Epidemiológico. 2016:47(13):1-15

3. Guimarães RM, Lobo Ade $P$, Siqueira EA, Borges TF, Melo SC Tuberculosis, HIV, and poverty: temporal trends in Brazil, the Americas, and worldwide. J Bras Pneumol. 2012;38(4): 511-7. https://doi.org/10.1590/S1806-37132012000400014

4. Conde MB, Melo FA, Marques AM, Cardoso NC, Pinheiro VG, Dalcin Pde T, et al. III Brazilian Thoracic Association Guidelines on tuberculosis. J Bras Pneumol. 2009;35(10):1018-48.

5. Blomberg B, Spinaci S, Fourie B, Laing R. The rationale for recommending fixed-dose combination tablets for treatment for tuberculosis. Bull World Health Organ. 2001;79(1):61-8.

6. Shin HJ, Know YS. Treatment of Drug Susceptible Pulmonary Tuberculosis. Tuberc Respir Dis (Seoul). 2015;78(3):161-7. https:// doi.org/10.4046/trd.2015.78.3.161

7. Mitchison DA. How drug resistance emerges as a result of poor compliance during short course chemotherapy for tuberculosis. Int J Tuberc Lung Dis. 1998;2(1):10-5.

8. Wu JT, Chiu CT, Wei YF, Lai YF. Comparison of the safety and efficacy of a fixed-dose combination regimen and separate formulations for pulmonary tuberculosis treatment. Clinics (Sao Paulo). 2015;70(6):429-34 https://doi.org/10.6061/clinics/2015(06)08

9. Ferreira $A C$, Silva Júnior JL, Conde MB, Rabahi MF. Clinical treatment outcomes of tuberculosis treated with the basic regimen recommended by the Brazilian Ministry of Health using fixed-dose combination tablets in the greater metropolitan area of Goiânia, Brazil. J Bras Pneumol. 2013;39(1):76-83. https://doi.org/10.1590/ S1806-37132013000100011

10. National Institute for Health and Care Excellence [homepage on the Internet]. London: the Institute c2016 [updated 2016 May; cited 2016 Jan 13] NICE Guideline 33. [about 3 screens]. Available from: www. nice.org.uk/guidance/ng33

11. Suryanto AA, van den Broek J, Hatta M, de Soldenhoff $R$, van de Werf MJ. Is there an increased risk of TB relapse in patients treated with fixed-dose combination drugs in Indonesia? Int J Tuberc Lung Dis. 2008;12(2):174-9.

12. Gravendeel JM, Asapa AS, Becx-Bleumink M, Vrakking HA Preliminary results of an operational field study to compare sideeffects, complaints and treatment results of a single-drug shortcourse regimen with a four-drug fixed combination (4FDC) regimen in South Sulawesi, Republic of Indonesia. Tuberculosis (Edinb). 2003;83(1-3):183-6. https://doi.org/10.1016/S1472-9792(02)00053-7

13. Lienhardt C, Cook SV, Burgos M, Yorke-Edwards V, Rigouts L, Anyo $G$, et al. Efficacy and safety of a 4-drug fixed-dose combination regimen compared with separate drugs for treatment of pulmonary tuberculosis: the Study C randomized controlled trial. JAMA 2011;305(14):1415-23. https://doi.org/10.1001/jama.2011.436

14. Bartacek A., Schütt D, Panosch B, Borek M; Rimstar 4-FDC Study Group. Comparison of a four-drug fixed-dose combination regimen with a single tablet regimen in smear-positive pulmonary tuberculosis. Int J Tuberc Lung Dis. 2009;13(6):760-6.

15. Monedero I, Caminero JA. Evidence for promoting fixed-dose combination drugs in tuberculosis treatment and control: a review. Int J Tuberc Lung Dis. 2011;15(4):433-9. https://doi.org/10.5588/ ijtld.09.0439

16. Maciel EL, Guidoni LM, Favero JL, Hadad DJ, Molino LP, Jonhson $J L$, et al. Adverse effects of the new tuberculosis treatment regimen recommended by the Brazilian Ministry of Health. J Bras Pneumol. 2010;36(2):232-8.

17. Hung CL, Chien JY, Ou CY. Associated factors for tuberculosis recurrence in Taiwan: a nationwide nested case-control study from 1998 to 2010. PLoS One. 2015;10(5):e 0124822.

18. Panjabi R, Comstock GW, Golub JE. Recurrent tuberculosis and its risk factors: adequately treated patients are still at high risk. Int $\mathrm{J}$ Tuberc Lung Dis. 2007;11(8):828-37

19. Crofts JP, Andrews NJ, Barker RD, Delpech V, Abubakar I. Risk factors for recurrent tuberculosis in England and Wales, 1998-2005 Thorax. 2010;65(4):310-4. https://doi.org/10.1136/thx.2009.124677 
Estimated rates of recurrence, cure, and treatment abandonment in patients with pulmonary tuberculosis treated with a four-drug fixed-dose combination regimen at a tertiary health care facility in the city of Rio de Janeiro, Brazil

20. Jo KW, Yoo JW, Hong Y, Lee JS, Lee SD, Kim WS, et al. Risk factors for 1-year relapse of pulmonary tuberculosis treated with a 6-month daily regimen. Respir Med. 2014;108(4):654-9. https://doi. org/10.1016/j.rmed.2014.01.010

21. Mallory KF, Churchyard GJ, Kleinschmidt I, De Cock KM, Corbett EL. The impact of HIV infection on recurrence of tuberculosis in South African gold miners. Int J Tuberc Lung Dis. 2000;4(5):455-62.

22. Wallis RS, Peppard T, Hermann D. Month 2 culture status and treatment duration as predictors of recurrence in pulmonary tuberculosis: model validation and update. PLOS One. 2015;10(4):e0125403. https://doi.org/10.1371/journal.pone.0125403

23. Blomberg B, Fourie B. Fixed-dose combination drugs for tuberculosis application in standardised treatment regimens. Drugs. 2003;63(6):53553. https://doi.org/10.2165/00003495-200363060-00002

24. Reed GW, Choi H, Lee YS, Lee M, Kim Y, Park H, et al. Impact of diabetes and smoking on mortality in tuberculosis. PLoS One. 2013;8(2):e58044. https://doi.org/10.1371/journal.pone.0058044

25. Albanna AS, Smith BM, Cowan D, Menzies D. Fixed-dose combination antituberculosis therapy: a systematic review and meta-analysis. Eur Respir J. 2013;42(3):721-32. https://doi. org/10.1183/09031936.00180612

26. Nunn AJ, Cook SV, Burgos M, Rigouts L, Yorke-Edwards V, Anyo $G$, et al. Results at 30 months of a randomised trial of FDCs and separate drugs for the treatment of tuberculosis. Int J Tuberc Lung Dis. 2014;18(10):1252-4. https://doi.org/10.5588/ijtld.14.0281

27. Gallardo CR, Rigau Comas D, Valderrama Rodríguez A, Roqué Figuls M, Parker LA, Caylà J, et al. Fixed-dose combinations of drugs versus single-drug formulations for treating pulmonary tuberculosis Cochrane Database Syst Rev. 2016;(5):CD009913. https://doi. org/10.1002/14651858.cd009913.pub2 